\title{
ЮРИДИЧЕСКАЯ ТЕХНИКА
}

УДК 340, ББК 67.0, ГРНТИ 10.01.33., КОД ВАК 10.02.19

О. Е. Авилова, Ю. В. Печатнова

Барнаул, Россия

\section{О НЕКОТОРЫХ АСПЕКТАХ ПЕРЕВОДА МЕЖДУНАРОДНЫХ ДОКУМЕНТОВ}

\section{НА РУССКИЙ ЯЗЫК}

В статье рассматриваются проблемы толкования международных документов, переведенных на русский язык. Актуальность работы подтверждается тенденциями к глобализациии и, как следствие, к интернационализации права, которые способствуют активному нормотворчеству и применению норм международного права. Авторами предлагается краткая характеристика проблем толкования русскоязычных нормативных текстов и на этом фоне обозначается вдвойне серьезная проблема, связанная с толкованием англоязычных текстов, переведенных на русский язык. В качестве объекта для анализа взята Европейская конвенция по правам человека 1950 года в англоязычной и русскоязычной версиях. Выбор данного документа для изучения обосновывается приведенными в статье статистическими данными, подтверждающими многократность использования Конвенции в российской судебной практике, а также ее значительное влияние на развитие законодательства Российской Федерации. Исследование проводится путем сопоставления текстов указанного международного соглашения на английском и русском языках. Результатом проведенного анализа стало обнаружение некоторых неточностей при переводе принцииально важных положений Конвенции, которые могут повлечь неверное применение норм международного права. Авторы приходят к выводу о том, что ошибки перевода - явление немногочисленное, но, тем не менее, служащее показателем необходимости совершенствования существующей техники перевода международных документов на русский язык. На сегоднямний день большинство рекомендаций по технике перевода документов носят сугубо лингвистический характер. Видится необходимым оснащение существующих рекомендаџий по переводу международных документов правилами юридического характера. Следовательно, важна совместная работа лингвистов и юристов 
по разработке правил перевода международных документов.

Ключевые слова: перевод, международный документ, Европейская конвенция по правам человека.

Сведения об авторе: Оксана Евгеньевна Авилова, кандидат юридических наук, доцент кафедры теории и истории государства и права Алтайского государственного университета. 656049, Барнаул, пр-m Социалистический, 68. E-mail: avilovaoksana@rambler.ru

Сведения об авторе: Юлия Вадимовна Печатнова, студентка 4 курса юридического института Алтайского государственного университета. 656049, Барнаул, пр-т. Социалистический, 68. E-mail: eclipsej@mail.ru

O. E. Avilova, Yu. V. Pechatnova

Barnaul, Russia

ON SOME ASPECTS OF TRANSLATION OF THE INTERNATIONAL DOCUMENTS INTO THE RUSSIAN LANGUAGE

The article is dedicated to the problems of the reading the international documents translated into Russian. The urgency of the work is confirmed by the tendencies of globalization and, as a consequence, the internationalization of law, which promotes active rulemaking and application the norms of international law. The authors outline the problems of interpreting Russian-language normative texts and, on this background, appears a twice more serious problem, associated with the interpretation of English-language texts translated into Russian. The European Convention of Human Rights of 1950 in the English-language and Russian-language versions was chosen as the object for analysis. The choice of this document for study is justified by the statistical data, which confirms frequent use of the Convention in Russian judicial practice, as well as its significant influence on the development of the Russian Federation legislation. The study is carried out by comparing two texts of this international covention in English and Russian. The result of the analysis is the revealing of some inaccuracies in the translation of the fundamentally important provisions in the Convention, which may lead to incorrect implementation of the norms of international law. The authors come to the conclusion that mistakes in translation are rather scarce, but nevertheless they indicate the need to improve the existing technique of translating international documents into Russian. Nowadays most of the recommendations on the technology of translating the documents are purely linguistic. It seems necessary to enhance the existing recommendations on the translation of international documents by the rules of legal nature. Therefore, it is important that linguists and lawyers develop rules for the translation of international documents together.

Key words: translation, international document, European Convention of Human Rights. 
About the author: Oksana Evgenievna Avilova, Candidate of Law, Associate Professor of the Chair of Theory and History of State and Law, Altai State University. 656049, Barnaul, Prospect Socialisticheskiy, 68. E-mail: avilova-oksana@rambler.ru

About the author: Yulia Vadimovna Pechatnova, a fourth-year student of Law institute, Altai State University.656049, Barnaul,Prospect Socialisticheskiy,68.E-mail: eclipsej@mail.ru

Превалирование международного права над внутригосударственным можно назвать современным демократическим трендом, отраженным в Конституциях государств в качестве одной из основ правового государства. Интернационализации права, отчетливо наблюдающейся на современном этапе развития юриспруденции, сопутствует повышение значения международных нормативно-правовых актов.

Применение норм международного права осложняется особенностями перевода международных нормативно-правовых актов, в процессе которого неизбежна подмена юридических конструкций международного права на юридические понятия национального права. Основная причина — отсутствие эквивалентного понятия в национальном праве. В случае, когда перевод юридического понятия максимально приближен к оригиналу, толкование юридического термина может быть неодинаковым в различных государствах ввиду принадлежности государств к разным правовым семьям, влияния государственной политики.

Проиллюстрировать многоаспектность разногласий, связанных с интерпретацией правовых понятий, позволяет наглядный пример. Зачастую значение юридических терминов не совпадает с их буквальным, словарным определением даже в рамках одного языка. Так, например, в толковом словаре С. И. Ожегова понятие «особая жестокость» имеет значение «крайняя степень суровости и беспощуадности» [Ожегов 1997], в то время как в Постановлении Пленума Верховного Суда РФ от 27.01.1999 «О судебной практике по делам об убийстве (ст. 105 УК РФ)» понятие «особая жестокость» имеет более узкое значение. Так, расчленение или уничтожение трупа, а также глумление над трупом не охватываются значением данного термина с точки зрения 
юридического толкования, но вышеперечисленные деяния вполне соответствуют определению, предлагаемому толковым словарем и, действительно, выражают крайнюю степень беспощадности и суровости. Уже на этой стадии возникает проблема соотношения русского и юридического русского языка; в результате становится затруднительно понять, где заканчивается простое убийство и начинается убийство с особой жестокостью.

С выходом за рамки внутригосударственного права степень сложности толкования термина возрастает. В Кодексе США используется понятие «abuse» («жестокость») и дается его определение с точки зрения американского законодательства: «the term means intentionally or knowingly causing death or serious bodily injury» («nреднамеренное или сознательное причинение смерти или серьезное телесное повреждение»), пп. 3 п. «а» параграфа 1111 Кодекса США [U.S. Code, URL]. В Оксфордском толковом словаре понятие «abuse» характеризуется как «treat with cruelty or violence, especially regularly or repeatedly» («бессердечное или с физическим насилием обращуение, особенно регулярное или неоднократное») [English Oxford living Dictionaries, URL].

Следовательно, одна и та же конструкция в текстах разных документов наполняется неодинаковым содержанием. Небольшое исследование уже выявило четыре интерпретации понятия «жестокость»: с точки зрения русского языка, юридического русского языка, английского языка и американского юридического языка. Таким образом, чтобы перенести юридический термин в сферу международно-правового регулирования, необходим узкоспециализированный комплексный юридическо-лингвистический перевод. Однако, несмотря на длительное международное сотрудничество России с зарубежными государствами, количество исследований по технике перевода международных официальных документов весьма немногочисленно. Между тем, специфика перевода международных актов постепенно занимает все более значительное место в политико-правовой конъюнктуре.

Так, 3. 3. Чанышева [Чанышева 2017: 60] предлагает рассматривать перевод текстов политического содержания как акт идеологической диверсии, 
используемой в целях контроля над информационным пространством целевой аудитории. Автор иллюстрирует деструктивную роль перевода исходного текста, подвергнутого переводчиком субъективной интерпретации, анализирует приемы смысловых искажений на материале сопоставительного анализа английских оригинальных статей и их версий на русском языке. Логично предположить, что перевод текстов правового содержания может вызывать не менее неоднозначные толкования, однако еще более ощутимые последствия.

В качестве объекта для терминологического анализа возьмем текст Европейской конвенции по правам человека 1950 года на русском и английском языках. Сторонами данного соглашения выступают страны-участницы Совета Европы, в число которых входит Российская Федерация. Членство в данной международной организации подразумевает распространение на стран-участниц юрисдикции Европейского суда по правам человека (ЕСПЧ). Выбор в пользу данного международного соглашения сделан ввиду существенной роли, которую играет Конвенция для законодательства многих государств. Статистические исследования показывают, что Российская Федерация стабильно лидирует среди стран Совета Европы по числу нарушений прав человека, подтвержденных Европейским судом. Более того, прецедентная практика ЕСПЧ оказывает реальное влияние на развитие российского права. Это обусловлено тем, что содержащиеся в актах ЕСПЧ правоположения учитываются при совершенствовании национального законодательства, а также в правоприменительной деятельности органов государств - участников Конвенции.

При вынесении постановлений Европейский суд ссылается исключительно на положения Европейской конвенции, прибегая к толкованию указанного соглашения. Однако сравнительный анализ русскоязычной и англоязычной версий Конвенции демонстрирует расхождение в терминологии, которое еще более усиливается при последующем толковании соглашения.

Во-первых, статья 5 Европейской конвенции по правам человека в русскоязычном варианте именуется «Право на свободу и личную 
неприкосновенность », в англоязычном — «Right to liberty and security» («nраво на свободу и безопасность»). Таким образом, переводчик ставит знак равенства между терминами «личная неприкосновенность»и «security» («безопасность»). Между тем это два совершенно различных юридических понятия, которые не должны смешиваться.

Оксфордский словарь английского языка определяет «security» («безопасность, охрана, защита») как, во-первых, «The state of being free from danger or threat» («состояние свободы от опасности или угрозы»»), во-вторых, «The safety of a state or organization against criminal activity» («безоnасность государства или организаџии от преступности») [English Oxford living Dictionaries, URL].

Таким образом, английская версия акцентирует внимание на государстве, которому обеспечивается охрана от внешних и внутренних угроз, вызванных преступностью. В русскоязычной версии внимание сосредоточено на личности, которой гарантируется неприкосновенность, а значит недопустимость вмешательства, в том числе со стороны органов государственной безопасности.

Во-вторых, в статье 7 Конвенции выражение the general principles of law в русском эквиваленте интерпретируется как общие принц̧ипь пррава. В данном случае переводчик приравнивает понятия «law» («закон») и «право». Дословный перевод может спровоцировать ложное восприятие нормы, что недопустимо, так как «общие принципы права» - это более широкое понятие для толкования, чем общие принципы законодательства государства. Соотношение данных понятий в разных государствах неодинаково и зависит от преобладающего типа правопонимания в той или иной национальной правовой системе. Однако поставленный знак равенства между понятиями объясняется не легальным закреплением нормативистского правопонимания на международном уровне, а скорее лингвистической причиной. Понятие «law» («закон») имеет более широкое значение в английском языке, чем понятие «закон» - в русском. Термин «law» может обозначать как право, так и закон. Слова, близкие по значению к слову «law», такие как «rule» («правило»), «right» («право») хотя и кажутся более 
подходящими, но не отражают того смысла, который заложен в категории «право» в российском законодательстве. Так, слово «right» («право»), как ни удивительно, несет иную смысловую нагрузку и используется для обозначения прав, привилегий и законных интересов, например, «right to life» («право на жизнь»). Итак, приведенный пример демонстрирует не столько неточность перевода, сколько невозможность осуществить точный перевод в виду отсутствия в английском языке понятия, эквивалентного понятию «право» в русском языке.

В-третьих, остановимся на использовании понятия «собственность» в Конвенции, точнее в тексте Протокола № 1 к ней.

В русскоязычной версии статья 1 Протокола №1 именуется как «Защฺита собственности» и начинается со слов «Каждое физическое или юридическое лицуо имеет право на уважение своей собственности» [Конвенция ... URL]. B названии и в тексте статьи используется одно и то же слово - собственность. В англоязычной версии содержится заголовок «Protection of property». «Property» означает «собственность» или «имущество». Исходя из логики правовой нормы, в первом предложении должен быть использован идентичный термин. Однако статья начинается так: «Every natural or legal person is entitled to the peaceful enjoyment of his possessions» [European Convention ... URL]. Появляется новый термин, подменяющий понятие «property», - «possessions». Слово «possession» обозначает скорее «владение», которое является лишь элементом в праве собственности с точки зрения российской цивилистики.

Во втором предложении статьи 1 Протокола № 1 к Конвенции вновь используется термин «рossessions»: «No one shall be deprived of his possessions» [European Convention ...: URL]. Однако перевод данного предложения на русский вносит новое значение указанного слова и звучит так: «Никто не может быть лишен своего имушества» [Конвенция ... URL]. Итак, термин «possessions», близкий по значению с понятием «владение», в переводе сначала преобразуется в термин «собственность», затем - в категорию «имущество». Между тем, в названии статьи используется уже другое английское «property», и 
все то же русское «собственность».

При небольшой погрешности перевода неточность, размытость, неоднозначность юридического наполнения категории «собственность» имеют весьма серьезные последствия, препятствуя пониманию и применению Протокола № 1 к Конвенции. Данная проблема особенно заметна при прочтении перевода постановлений ЕСПЧ по конкретным делам.

Например, перевод Постановления ЕСПЧ от 15 января 2009 г. по делу «Бурдов против России», содержит следующий фрагмент: «Суд вновь напоминает, что «судебный иск» может пониматься как «собственность» по смыслу статьи 1 Протокола № 1 к Конвенции в случае, если в достаточной мере установлено, что оно может быть юридически реализовано» [Постановление ЕСПЧ от 15 января 2009 г.: URL].

В переводах иных постановлений по жалобам против России встречается указание на то, что «требование» тоже может пониматься как «собственность» по смыслу статьи 1 Протокола № 1 к Конвенции. Например, в постановлении ЕСПЧ от 7 мая 2003 г. по делу «Тимофеев против России».

Как отмечает М. А. Рожкова [Рожкова 2006: 58], возможно, было бы допустимо смириться с употреблением в Конвенции термина «собственность» в значении «имущество» и с определенной долей условности использовать его. Однако некоторые авторы идут дальше и заявляют уже об автономном значении права собственности, которое придано ему в практике ЕСПЧ и которое не совпадает с принятым в национальных правовых системах. Речь идет об отождествлении объекта собственности (имущества) с правом собственности, что недопустимо с точки зрения современного гражданского права.

Более того, в результате подобного смешения создается впечатление, что содержанием статьи 1 Протокола № 1 к Конвенции сужается круг имущества, права на которое по смыслу статьи 1 Протокола № 1 к Конвенции подлежат защите. Однако общая концепция международного соглашения свидетельствует об обратном. ЕСПЧ, являясь единственным органом, уполномоченным официально толковать и разъяснять весьма краткие формулировки положений 
Конвенции и Протоколов к ней, реализуя эту компетенцию, тем самым расширяет границы действия Конвенции и наполняет ее положения новым смыслом. ЕСПЧ весьма широко толкует понятие «имущество» (или, как указано в официальном переводе на русский язык Протокола №1 к Конвенции, понятие «собственность»), обобщая все передовые тенденции, намечающиеся в национальных правовых системах европейских стран. Однако формально и юридически неточный перевод положений международного соглашения порождает негативные последствия в правоприменении, искажает значение правоположений и не позволяет уяснить их истинный смысл.

Подводя итоги, отметим следующее.

Во-первых, тенденции к глобализации и, как следствие, к интернационализации права, способствуют активному нормотворчеству и применению норм международного права. В этой связи следует уделять повышенное внимание переводу международных актов на национальные языки во избежание искажения исходного текста.

Во-вторых, положительным результатом исследования оригинала и перевода Европейской конвенции по правам человека можно счесть установление того, что лингвистические изъяны немногочисленны. Негативные выводы анализа текста международного соглашения состоят в том, что встречающиеся периодически неточности перевода не отражают действительного содержания нормы права, препятствуют ее правильному пониманию и применению, затрудняя реализацию гарантированных Конвенцией прав.

В этой связи необходимо совершенствование техники перевода международных документов на русский язык. При переводе юридического термина с одного языка на другой необходимо производить не только лингвистический перевод, но и юридический, то есть наполнять словестную оболочку единообразным юридическим содержанием. 
1. English Oxford living Dictionaries. URL: https://en.oxforddictionaries.com/

2. European Convention Human. URL: https://www.echr.coe.int/Pages/home.aspx?p=basictexts\&c=\#n1359128122487_pointer

3. Statistics by State. URL: https://www.echr.coe.int/Pages/home.aspx?p=reports\&c=\#n1347956587550_pointer

4. U.S. Code. URL: https://www.law.cornell.edu/uscode/text

5. Конвенция о защите прав человека и основных свобод от 04.11.1950 г. URL: http: //www.consultant.ru

6. О судебной практике по делам об убийстве (ст.105 УК РФ): постановление Пленума

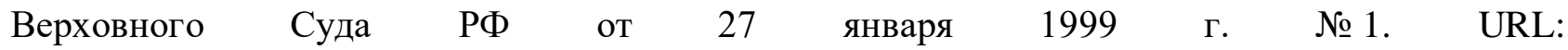
http://www.garant.ru/products/ipo/prime/doc/1251642/\#ixzz5QivF3icN

7. Ожегов С. И. Толковый словарь русского языка. М., 1997.

8. Постановление Европейского суда по правам человека от 15 января 2009 г. Дело Бурдов против России. URL: http : //www.consultant.ru

9. Постановление ЕСПЧ от 3 ноября 2005 г. Дело Кукало против России. URL: http : //www.consultant.ru

10. Постановления ЕСПЧ от 7 мая 2003 г. Дело Тимофеев против России. URL: http : //www.consultant.ru

11. Рожкова M. A. К вопросу о понятии «собственность» в Конвенции О защите прав человека и основных свобод и практике Европейского Суда по правам человека. Журнал российского права. 2006. № 12. С. 58-65.

12. Старженецкий В. В. Россия и Совет Европы: право собственности. М., 2004. С. 46.

13. Чанышева 3. 3. Перевод как инструмент идеологической диверсии в межкультурной политической коммуникации. Политическая лингвистика. 2017. № 5 (65). C. $60-65$.

\section{REFERENCES}

1. English Oxford living Dictionaries. URL: https://en.oxforddictionaries.com/
2. European
Convention
on
Human.
URL:

https://www.echr.coe.int/Pages/home.aspx?p=basictexts\&c=\#n1359128122487_pointer

3. Statistics

by

State.

URL:

https://www.echr.coe.int/Pages/home.aspx?p=reports\&c=\#n1347956587550_pointer

4. U.S. Code. URL: https://www.law.cornell.edu/uscode/text

5. Convention for the Protection of Human Rights and Fundamental Freedoms of November 4, 1950. [Konvenciya o zashchite prav cheloveka i osnovnyh svobod ot 4.11.1950 g]. URL: http : 
//www.consultant.ru

6. On judicial practice in cases of murder (Article 105 of the Criminal Code): Resolution of the Plenum of the Supreme Court of the Russian Federation of January 27, 1999 No 1. [O sudebnoj praktike po delam ob ubijstve (st.105 UK RF) : postanovlenie Plenuma Verhovnogo Suda RF ot 27 $\begin{array}{llll}\text { yanvarya } & 1999 & \text { g. № 1]. } & \text { URL: }\end{array}$ http://www.garant.ru/products/ipo/prime/doc/1251642/\#ixzz5QivF3icN

7. Ozhegov S. I. Explanatory dictionary of the Russian language [Tolkovyj slovar' russkogo yazyka]. Moscow, 1997

8. Judgment of the European Court of Human Rights on 15 January 2009 The case of Burdov v. Russia [Postanovlenie Evropejskogo suda po pravam cheloveka ot 15 yanvarya 2009 g. Delo Burdov protiv Rossii]. URL: http: //www.consultant.ru

9. The judgment of the European Court of Human Rights on 3 November 2005 The Case of Kukalo v. Russia [Postanovlenie Evropejskogo suda po pravam cheloveka ot 3 noyabrya 2005 g. Delo Kukalo protiv Rossii]. URL: http: //www.consultant.ru

10. The judgment of the European Court of Human Rights on 7 May 2003. The case Timofeev v. Russia [Postanovlenie Evropejskogo suda po pravam cheloveka ot 7 maya 2003 g. Delo Timofeev protiv Rossii]. URL: http: //www.consultant.ru

11. Rozhkova M. A. On the concept of «property» in the Convention on the Protection of Human Rights and Fundamental Freedoms and the practice of the European Court of Human Rights. [K voprosu o ponyatii «sobstvennost'» v Konvencii O zashchite prav cheloveka i osnovnyh svobod i praktike Evropejskogo Suda po pravam cheloveka]. Journal of Russian Law, 2006. No 12. Pp. 58-65.

12. Starzhenetsky V. V. Russia and the Council of Europe: ownership [Rossiya i Sovet Evropy: pravo sobstvennosti]. Moscow, 2004. P. 46.

13. Chanysheva Z. Z. Translation as a tool of ideological sabotage in intercultural political communication [Perevod kak instrument ideologicheskoj diversii v mezhkul'turnoj politicheskoj kommunikacii]. Political linguistics. 2017. No 5 (65). Pp. 60-65. 